in vivo $34: 2169-2172(2020)$

doi:10.21873/invivo.12025

\title{
Successful Management of Esophageal Cancer With Perforation Using Bypass Surgery Followed by Definitive Chemoradiotherapy
}

\author{
MANATO OHSAWA, YOICHI HAMAI, YUTA IBUKI, MANABU EMI and MORIHITO OKADA
}

Department of Surgical Oncology, Hiroshima University, Hiroshima, Japan

\begin{abstract}
Background: Esophageal perforation in advanced esophageal cancer requires immediate treatment. However, no clear treatment protocol has been established for this condition. We report a case of advanced esophageal cancer with esophageal perforation treated with esophageal bypass surgery and definitive chemoradiotherapy (CRT). Case Report: A 45-year-old woman was diagnosed with locally advanced esophageal cancer with esophageal perforation. Although the patient's general condition was relatively stable, no improvement was expected through conservative treatment. Esophageal gastric bypass surgery was performed; her symptoms improved postoperatively and oral ingestion became possible. Definitive CRT with 66 Gy radiotherapy and chemotherapy with cisplatin and 5-fluorouracil was administered. A complete clinical response was achieved. The patient is alive and well without recurrence 20 months after treatment. Conclusion: Definitive CRT after esophageal bypass surgery is a potential treatment option for locally advanced esophageal cancer with esophageal perforation to improve treatment response and quality of life.
\end{abstract}

Esophageal perforation may occur in patients with advanced esophageal cancer. Perforation due to esophageal cancer accounts for $1 \%$ of esophageal perforation cases (1). Although relatively rare, esophageal perforation is a serious and fatal complication in esophageal cancer patients, and such patients are unable to eat or drink. Immediate treatment is usually required. Esophagectomy or palliative treatment by esophageal

This article is freely accessible online.

Correspondence to: Yoichi Hamai, Department of Surgical Oncology, Hiroshima University, 1-2-3-Kasumi, Minami-ku, Hiroshima City, Hiroshima 734-8551, Japan. Tel: +81 822575869 , Fax: +81822567109, e-mail: yyhamai@hotmail.com

Key Words: Esophageal bypass, advanced esophageal cancer, esophageal perforation, definitive chemoradiotherapy. stenting or bypassing may be performed, but no clear treatment strategy has been established. Herein, we report a case of advanced esophageal cancer with esophageal perforation treated with chemoradiotherapy (CRT) after esophageal bypass surgery to highlight this as a potential treatment option.

\section{Case Report}

A 45-year-old woman visited a primary care doctor with the chief complaints of dysphagia and fever. Esophageal cancer was suspected after fluoroscopic examination, and she was referred to our hospital. Blood examination showed a high inflammatory response (white blood cell count: 14,540/ $\mu 1, \mathrm{C}-$ reactive protein level: $13.32 \mathrm{mg} / \mathrm{dl})$. Upper esophagogastroduodenoscopy showed a deep ulcerative lesion with a bulge $25 \mathrm{~cm}$ from the upper incisor and fistula formation within the ulcer. Computed tomography showed wall thickening with contrast enhancement in the middle thoracic esophagus, along with air and fluid retention in the surrounding mediastinum. The esophageal cancer invaded the pleura, and pneumonia was observed in the lower right lobe (Figure 1A, B). The patient was diagnosed with locally advanced esophageal cancer with esophageal perforation (cT4aN1M0 cStage IIIC according to the $7^{\text {th }}$ tumor, node, metastasis classification of the International Union Against Cancer) (2). The patient was forced to undergo fasting. A nasogastric tube was inserted for tube feeding management, and antibiotics were administered intravenously. Although the patient's general condition was relatively stable, no improvement was expected through conservative treatment. Accordingly, we decided to provide definitive CRT after esophageal bypass surgery.

The esophageal bypass procedure was performed as previously reported (Figure 2) (3). An upper midline abdominal incision was made with the patient in the supine position. A wide gastric tube prepared from the greater curvature or the whole stomach tube was used for reconstruction. The abdominal esophagus was divided, and a polyethylene tube was inserted into the esophagus and fixed via running absorbable sutures. The distal side of the 
A
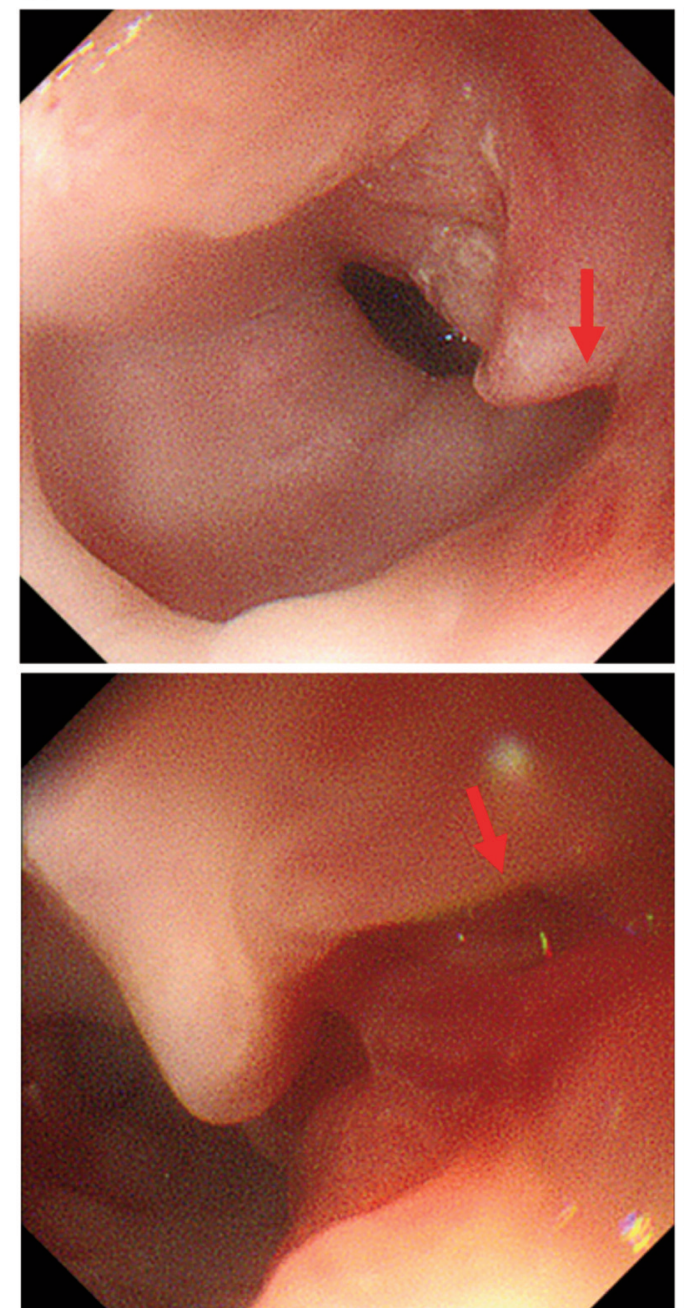

B
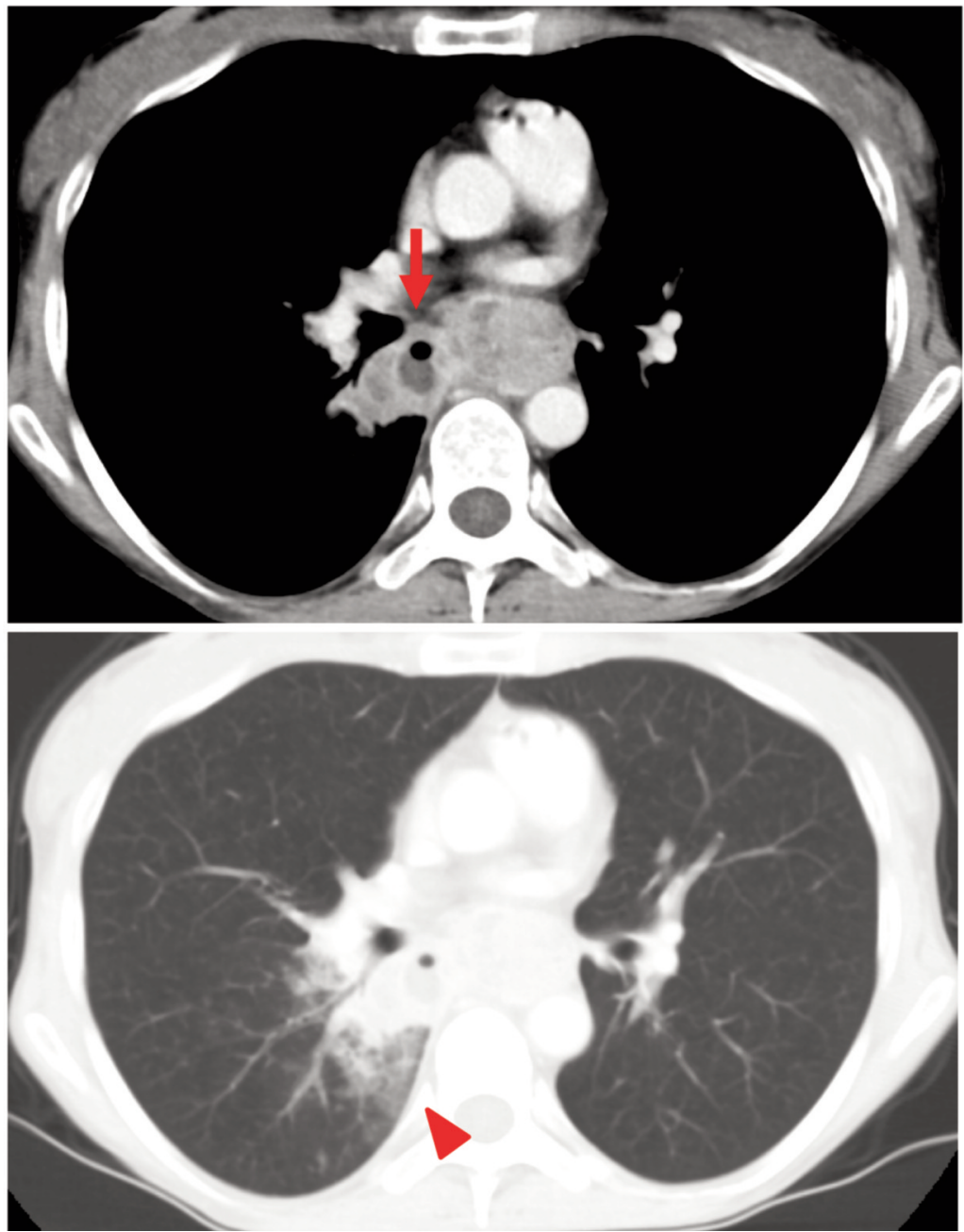

Figure 1. Endoscopic examination and computed tomography. (A) Upper esophagogastroduodenoscopy showing an ulcerative lesion and fistula formation within the ulcer. Arrow, perforated site in the middle thoracic esophagus. (B) Computed tomography showing locally advanced esophageal cancer with esophageal perforation. Arrow, mediastinal abscess containing air and fluid; Arrow head, pneumonia around mediastinal abscess.

polyethylene tube was brought out from the left hypochondrial region as a tube esophagostomy. Next, an incision was made in the left side of the neck, and the cervical esophagus was divided above the sternal notch. The esophageal stump was closed using a linear stapler. The gastric tube was then pulled up through the retrosternal route to the neck and anastomosed to the cervical esophagus using the hand-sewing technique. Drainage tubes were placed around the cervical anastomosis and in the left subphrenic space. A narrow 14-Fr drainage tube was inserted retrogradely through the tube esophagostomy into the remnant esophagus, and the tip of the narrow drainage tube was placed between the oral esophageal stump and the primary tumor to decompress and avoid rupture at the stump. The duration of surgery was $5 \mathrm{~h}$ and $46 \mathrm{~min}$, and the patient experienced $47 \mathrm{ml}$ of blood loss. The polyethylene tube was removed on postoperative days 21 , and the narrow drainage tube was retained.

After surgery, the patient's symptoms improved, and oral ingestion became possible. As saliva did not enter the perforation caused by the esophageal cancer, the inflammatory response also improved. There were no dietary restrictions, which improved the patient's postoperative quality of life. After surgery, we administered definitive CRT with 66 Gy radiotherapy and 2 cycles of chemotherapy with cisplatin and 5 -fluorouracil $\left(70 \mathrm{mg} / \mathrm{m}^{2} /\right.$ day of cisplatin on days 1 and 29 and $700 \mathrm{mg} / \mathrm{m}^{2} /$ day of 5-fluorouracil on days 1-4 and 29-32). A complete clinical response was achieved after CRT. Currently, 20 months after bypass surgery, the patient is undergoing follow-up care at the outpatient clinic, and she has not shown any relapse of esophageal cancer. 


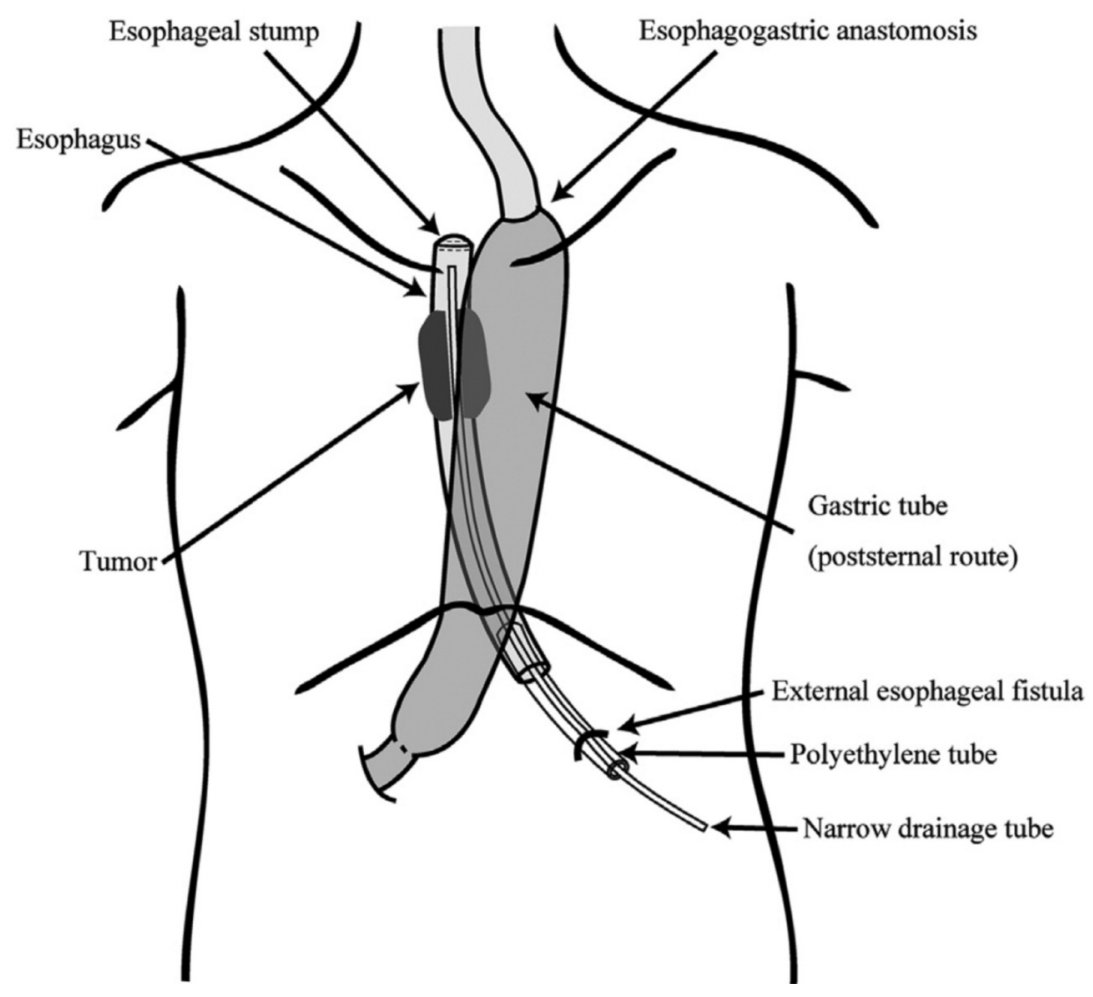

Figure 2. Schematic of the esophageal bypass procedure.

\section{Discussion and Conclusion}

No clear treatment strategy has been established for locally advanced esophageal cancer with esophageal perforation. In the current case, we performed CRT after esophageal bypass surgery. CRT using a total radiation dose of 50-66 Gy and 5fluorouracil plus cisplatin is the main treatment for unresectable locally advanced esophageal cancer. The prognosis of T4 esophageal cancer is generally poor; however, a complete clinical response is observed in $24 \%-32 \%$ of patients, and the 5-year survival rate is 7\%-14\% after definitive CRT (4-9). It is difficult to perform CRT in patients with esophageal perforation.

In our hospital, esophageal bypass surgery is performed before CRT to safely administer definitive CRT in esophageal cancer patients with tracheobronchial invasion (3). This treatment strategy seems to be effective for esophageal cancer with esophageal perforation, as observed in the current case. Treatment measures for this particular complication are important in esophageal cancer treatment. Moreover, completion of CRT is among the most important factors for favorable outcomes in these patients.

During gastric tube reconstruction, the drainage of secretions from the remnant esophagus is a problem, although internal and external esophageal drainage can be used to resolve this issue (10-13). In our hospital, external drainage is chosen due to the risk associated with aspiration of digestive juices if tracheal or tracheobronchial invasion occur.

Other treatment strategies for locally advanced esophageal cancer with esophageal perforation should also be considered. Esophageal perforation is usually treated palliatively via symptomatic treatment using esophageal stents. Stenting is a relatively simple and minimally invasive procedure. However, the clinical results of stent therapy are not satisfactory. After stent therapy, most patients can eat only semisolid food, and fistula formation due to pressure from the stent is a common complication. Other early, life-threatening complications have also been reported (14-18). Even if stent placement and fistula closure are successful, radiotherapy is not recommended, because radiotherapy after esophageal stent placement leads to a high risk of life-threatening complications $(19,20)$. Radical esophagectomy is difficult if there is infiltration into the surrounding organs, as in this case. Treatment with drainage alone is a relatively simple surgical procedure, but the quality of life is low because patients are unable to eat or drink. CRT with tube feeding management is possible in patients with nasogastric tubes, but quality of life is also low. An optimal treatment strategy for locally advanced esophageal cancer with esophageal perforation would improve the tumor control rate while alleviating the symptoms. We believe that the treatment option used in this case resulted in the best possible outcome for this patient. 
In conclusion, we safely administered definitive CRT after esophageal bypass surgery in a patient with locally advanced esophageal cancer with esophageal perforation. This type of surgery is a potential treatment option for patients with locally advanced esophageal cancer with esophageal perforation to improve treatment response and quality of life.

\section{Conflicts of Interest}

The Authors have no commercial support or conflicts of interest to disclose regarding this study.

\section{Authors' Contributions}

MO and YH drafted the article. MO, YH, YI, and ME contributed to patient care. $\mathrm{MO}$ and $\mathrm{YH}$ performed the literature search. MO, YH, YI, ME, and MO participated in the critical revision of the article. All the Authors read and approved the final article.

\section{References}

1 Brinster CJ, Singhal S, Lee L, Marshall MB, Kaiser LR and Kucharczuk JC: Evolving options in the management of esophageal perforation. Ann Thorac Surg 77(4): 1475-1483, 2004. PMID: 15063302. DOI: 10.1016/j.athoracsur.2003.08.037

2 Sobin LH, Gospodarowicz MK and Wittekind C: TNM Classification of Malignant Tumours. $7^{\text {th }}$ ed. Hoboken, NJ, Wiley-Blackwell, 2011.

3 Hihara J, Hamai Y, Emi M, Aoki Y, Taomoto J, Miyata Y and Okada M: Esophageal bypass operation prior to definitive chemoradiotherapy in advanced esophageal cancer with tracheobronchial invasion. Ann Thorac Surg 97(1): 290-295, 2014. PMID: 24200399. DOI: 10.1016/j.athoracsur.2013.08.060

4 Makino T and Doki Y: Treatment of T4 esophageal cancer. Definitive chemo-radiotherapy vs chemo-radiotherapy followed by surgery. Ann Thorac Cardiovasc Surg 17(3): 221-228, 2011. PMID: 21697781. DOI: 10.5761/atcs.ra.11.01676

5 Seto Y, Chin K, Gomi K, Kozuka T, Fukuda T, Yamada K, Matsubara T, Tokunaga M, Kato Y, Yafune A and Yamaguchi T: Treatment of thoracic esophageal carcinoma invading adjacent structures. Cancer Sci 98(7): 937-942, 2007. PMID: 17441965. DOI: $10.1111 / j .1349-7006.2007 .00479 . x$

6 Fujita H, Sueyoshi S, Tanaka T, Tanaka Y, Matono S, Mori N, Shirouzu K, Yamana H, Suzuki G, Hayabuchi N and Matsui M: Esophagectomy: is it necessary after chemoradiotherapy for a locally advanced T4 esophageal cancer? Prospective nonrandomized trial comparing chemoradiotherapy with surgery versus without surgery. World J Surg 29(1): 25-30, 2005. PMID: 15599735. DOI: 10.1007/s00268-004-7590-2

7 Nishimura Y, Suzuki M, Nakamatsu K, Kanamori S, Yagyu Y and Shigeoka H: Prospective trial of concurrent chemoradiotherapy with protracted infusion of 5-fluorouracil and cisplatin for T4 esophageal cancer with or without fistula. Int J Radiat Oncol Biol Phys 53(1): 134-139, 2002. PMID: 12007951. DOI: 10.1016/s0360-3016(01)02813-9

8 Kaneko K, Ito H, Konishi K, Kurahashi T, Ito T, Katagiri A, Yamamoto T, Kitahara T, Mizutani Y, Ohtsu A and Mitamura K: Definitive chemoradiotherapy for patients with malignant stricture due to $\mathrm{T} 3$ or $\mathrm{T} 4$ squamous cell carcinoma of the oesophagus. Br J Cancer 88(1): 18-24, 2003. PMID: 12556953. DOI: $10.1038 /$ sj.bjc.6600684

9 Ohtsu A, Boku N, Muro K, Chin K, Muto M, Yoshida S, Satake M, Ishikura S, Ogino T, Miyata Y, Seki S, Kaneko K and Nakamura A: Definitive chemoradiotherapy for T4 and/or M1 lymph node squamous cell carcinoma of the esophagus. J Clin Oncol 17(9): 2915-2921, 1999. PMID: 10561371. DOI: 10.1200/ JCO.1999.17.9.2915

10 Postlethwait RW: Technique for isoperistaltic gastric tube for esophageal bypass. Ann Surg 189(6): 673-676, 1979. PMID: 453939. DOI: $10.1097 / 00000658-197906000-00001$

11 Ong GB and Kwong KH: Management of malignant esophagobronchial fistula. Surgery 67(2): 293-301, 1970.

12 Hirai T, Yamashita Y, Mukaida H, Kawano K, Toge T, Niimoto $\mathrm{M}$ and Hattori T: Bypass operation for advanced esophageal cancer - an analysis of 93 cases. Jpn J Surg 19(2): 182-188, 1989. PMID: 2724717 . DOI: $10.1007 /$ bf02471583

13 Seto Y, Yamada K, Fukuda T, Hosoi N, Takebayashi R, Chin K, Kotsuka T, Gomi K and Yamaguchi T: Esophageal bypass using a gastric tube and a cardiostomy for malignant esophagorespiratory fistula. Am J Surg 193(6): 792-793, 2007. PMID: 17512299. DOI: 10.1016/j.amjsurg.2006.07.023

14 Abadal JM, Echenagusia A, Simo G and Camuñez F: Treatment of malignant esophagorespiratory fistulas with covered stents. Abdom Imaging 26(6): 565-569, 2001. PMID: 11911165. DOI: $10.1007 / \mathrm{s} 002610000193$

15 Nomori H, Horio H, Imazu Y and Suemasu K: Double stenting for esophageal and tracheobronchial stenoses. Ann Thorac Surg 70(6): 1803-1807, 2000. PMID: 11156075. DOI: 10.1016/s00034975(00)02042-7

16 Nam DH, Shin JH, Song HY, Jung GS and Han YM: Malignant esophageal-tracheobronchial strictures: parallel placement of covered retrievable expandable nitinol stents. Acta Radiol 47(1): 3-9, 2006. PMID: 16498926. DOI: 10.1080/02841850500334989

17 Lecleire S, Antonietti M, Di Fiore F, Ben-Soussan E, Bota S, Hellot MF, Thiberville L, Michel P, Lerebours E and Ducrotté P: Double stenting of oesophagus and airways in palliative treatment of patients with oesophageal cancer is efficient but associated with a high morbidity. Aliment Pharmacol Ther 25(8): 955-963, 2007. PMID: 17403000. DOI: 10.1111/j.1365-2036.2007.03280.x

18 Hamai Y, Hihara J, Emi M, Okita R, Shimizu K and Okada M: Successful management of multiple esophagorespiratory fistulas using two types of stent: report of a case. Surg Today 41(4): 560562, 2011. PMID: 21431494. DOI: 10.1007/s00595-009-4298-9

19 Nishimura Y, Nagata K, Katano S, Hirota S, Nakamura K, Higuchi F, Soejima T, Sai H and Japanese Society for Esophageal Diseases: Severe complications in advanced esophageal cancer treated with radiotherapy after intubation of esophageal stents: a questionnaire survey of the Japanese Society for Esophageal Diseases. Int J Radiat Oncol Biol Phys 56(5): 1327-1332, 2003. PMID: 12873677. DOI: 10.1016/s0360-3016(03)00198-6

20 Yakami M, Mitsumori M, Sai H, Nagata Y, Hiraoka M and Nishimura Y: Development of severe complications caused by stent placement followed by definitive radiation therapy for T4 esophageal cancer. Int J Clin Oncol 8(6): 395-398, 2003. PMID: 14663644. DOI: $10.1007 / \mathrm{s} 10147-003-0356-2$

Received March 18, 2020

Revised March 31, 2020

Accepted April 1, 2020 